\title{
Efeitos vizinhança e eficácia coletiva: a relevância do contexto na explicação sociológica
}

SAMPSON, Robert J. Great American City: Chicago and the enduring neighborhood effect. Chicago: University of Chicago Press, 2012.

Marcio Mattos*

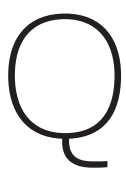
uão importante é o contexto para compreender fenômenos sociais e seus processos? Qual a relevância de desigualdades espaciais na organização da vida cotidiana das pessoas? Em Great American City: Chicago and the enduring neighborhood effect (GAC), o sociólogo Robert J. Sampson (Harvard University ${ }^{1}$ ), explora com rigor e precisão metodológicos e conceituais as respostas tradicionais para essas (e diversas outras) questões. Numa palavra, Sampson considera que "neighborhoods contexts are socially productive - important determinants of the quantity and quality of human behavior in their own rights" 2 (p. 358), numa referência à estabilidade que marca as desigualdades da vida urbana. Longe de ser um jogo de palavras, o autor leva especialmente a sério em toda a obra a definição de vizinhança como unidade de análise, produto e producente, de processos sociais com realidade e características específicas. A vizinhança, constitui, na obra, um mecanismo que per se estrutura a vida social da cidade. Com efeito, Sampson faz ecoar a tese de que vizinhanças importam, o que é apresentado de forma coerente e convincente.

A obra está presente em programas de pós-graduação brasileiros, entretanto pode ser ainda mais amplamente explorada. As possibilidades são diversas e não se pretende exauri-las nesse texto, contudo GAC é recomendada para sociólogos, especialmente aqueles interessados em sociologia urbana, demógrafos, geógrafos e ainda cientistas políticos. A influência dos conceitos apresentados por Robert Sampson tem sido especialmente relevante em estudos de criminologia, saúde pública e educação. O texto é denso e requer atenção para seguir a argumentação e suas implicações, bem como as notas explicativas e os gráficos ${ }^{3}$. Como William Julius Wilson (1987), autor de Truly disadvantaged, antecipa no prefácio, GAC representa uma teoria sistemática dos efeitos vizinhança, em que a rigorosa apresentação de evidências permite que se percebam estabilidades mesmo em cenários de transformações sociais e mudanças macroeconômicas (p. viii).
* Doutorando

em sociologia do Programa de Pós-Graduação em Sociologia da Universidade de Brasília (PPGSOL/ UnB), desenvolvendo pesquisa na linha de violência, segurança e cidadania.

Pesquisador visitante na University of Massachusetts Boston, com apoio da Comissão Fulbright e da Coordenação de Aperfeiçoamento de Pessoal de Nível Superior (Capes). <mjmattos@gmail. com>.

1. Como é demonstrado brevemente no Capítulo 4, a obra representa também o desenvolvimento intelectual e profissional do próprio autor. Tendo participado do Project on Human Development in Chicago Neighborhoods (PHDCN) desde 1988, portanto seis anos após o seu início, Robert Sampson também assume nesse ano sua primeira posição acadêmica 
no Departamento de Sociologia da Universidade de Chicago. Já em 1991, torna-se Full Professor e em 1994 assume a função de diretor científico do PHDCN. É também em 1994 que a primeira onda de coleta de dados do PHDCN se inicia, sendo repetida em 2002. Em 2003, Sampson se transfere para o Departamento de Sociologia de Harvard, onde permanece até hoje.

2. A opção por manter citações em língua inglesa se deve à busca por preservar o sentido original do autor.

\section{Estes - é} importante que se diga - são precisos e esclarecedores, mas deveriam ser maiores, de página inteira.

4. Na verdade, o projeto original foi denominado Project on Human Development in Chicago Neighborhoods (PHDCN), cujos estudos subsequentes ampliaram os objetivos originais e, também, os dados e os métodos utilizados (p. 71). Os dados do projeto original estão disponíveis para consulta em: <https://www.icpsr. umich.edu/icpsrweb/ PHDCN>.
Em termos gerais, o livro está dividido em cinco partes organizadas em 17 capítulos. A leitura começa com os aspectos conceituais (cap. 1 e 2) e metodológicos (cap. 3 e 4), com destaque para a profusão de dados coletados ao longo de quase duas décadas de pesquisas. Em termos de dados primários, o Chicago Project ${ }^{4}$ reuniu diferentes pesquisas: um survey longitudinal que acompanhou mais de 3.800 famílias, três ondas de surveys em nível comunitário com mais de 8.000 participantes, um survey com mais de 2.800 líderes comunitários, informações sobre eventos comunitários publicados em jornais ao longo de 30 anos (cap. 8), dados coletados a partir de gravações georreferenciadas de mais de 23 mil ruas e dados sobre um experimento que utilizou mais de 3.000 cartas perdidas (cap. 9). Além disso, Sampson se vale amplamente de dados censitários e registros criminais.

Para conferir coerência analítica à diversidade de dados coletados, o autor utiliza o que denominou ecometrics, abordagem que contempla medidas e formas de interpretação do contexto social e ecológico da cidade inspiradas na disciplina instrumentalizada da psicologia social (p. 60). O desenvolvimento de uma metodologia específica para medir os mecanismos vicinais, avaliando a dimensão ecológica da vida urbana, é dividido com outros autores, especialmente Stephen Raudenbush (Sampson, Raudenbush \& Earls, 1997).

Sob o ponto de vista teórico, Sampson se posiciona em um dos debates fundamentais das ciências sociais sobre agência e estrutura por meio do que denominou paradigma contextual (p. 68). Nesse momento, sua vinculação à Escola de Chicago vem à tona: o autor critica o individualismo metodológico que assume as vizinhanças como espaços em que os indivíduos adotam decisões autônomas (p. 358). A abordagem tipicamente holista é também afastada, por sugerir um determinismo artificial no contexto social. Nesse ponto, os argumentos da globalização e da deslocalização são criticados por meio da constatação de que as vizinhanças se diferenciam sistematicamente e o fazem com propriedades duráveis e mecanismos sociais e culturais de reprodução.

A estrutura social da cidade é marcada por uma lógica espacial durável que organiza a vida cotidiana dos indivíduos, os quais reagem a diferenças nas vizinhanças por meio de práticas e percepções que, por sua vez, ajudam a moldar mecanismos sociais independentes por si (p. 21). Metodologicamente, o autor não desconsidera o papel das escolhas individuais, mas as considera imbricadas no contexto social, tornando-as efeitos vizinhança em essência. Essa discussão é desenvolvida em detalhe no capítulo 12, no qual o autor defende a ideia de que "neighborhoods choose people rather than the common idea that people choose neighborhoods" (p. 327), numa referência direta à limitação de escolhas individuais em fronteiras concretas e 
tangíveis. Precisamente, esse é um dos fios condutores da análise de Sampson em todo o livro.

Nos capítulos 11 e 12, o sociólogo busca demonstrar a persistência de padrões nos comportamentos das pessoas em virtude dos efeitos vizinhança (como no caso de migrações internas e imigrações), com destaque para as relações encontradas entre segregação espacial e racial, dependência econômica e criminalidade. Em outras palavras, o autor confere centralidade ao contexto na explicação sociológica, resgatando a tradição da Escola de Chicago representada por autores como Robert Park e Ernest Burgess (1984), Louis Wirth (1997) e Clifford Shaw e Henry McKay (1969), sustentado em métodos inovadores e em substancial respaldo empírico.

Um dos instrumentos utilizados por Sampson para interpretar as diferenças entre as vizinhanças é o conceito de eficácia coletiva. Desenvolvida inicialmente em artigos amplamente conhecidos no campo criminológico (Sampson, Morenoff \& Earls, 1999; Sampson, Morenoff \& Gannon-Rowley, 2002), a noção de eficácia coletiva traz consigo os elementos de coesão social, expectativas compartilhadas em torno de controle social e a disposição para a ação coletiva. Em grande medida, o pressuposto da Teoria da Desorganização Social é resgatado, pela qual o controle social não é um atributo individual, mas antes produto da coletividade que se engaja em melhorar as condições de vida locais, tendo como resultado a redução de crimes e violências.

Contudo, Sampson se desvencilha da centralidade dos laços sociais e da densidade de contatos e privilegia interações sociais baseadas em confiança e expectativas compartilhadas. É uma atualização da urban village, em que as expectativas em torno da ação social são especialmente importantes na realização do controle social, superando a ideia nostálgica de que os vizinhos devem se conhecer e se relacionar periodicamente. Como exemplo, Sampson destaca a associação entre alta eficácia coletiva e reduzidos indicadores criminais, como homicídios e crimes contra o patrimônio em Chicago. No mesmo modelo, descrito na página 161, a eficácia coletiva foi ainda um mediador de outras características da vizinhança, como desvantagens concentradas e estabilidade residencial, medidas típicas da análise sob a ótica da desorganização social.

A relação entre a eficácia coletiva e os laços sociais merece ainda mais destaque, pois desloca o enfoque analítico para as expectativas compartilhadas (que são produtos de interações sociais) e para a capacidade de ação coletiva, as quais caracterizam as vizinhanças. Em última medida, os laços sociais são importantes, mas não definem as vizinhanças como a eficácia coletiva faz (Sampson, Raudenbush \& Earls, 1997). 
A abordagem de Sampson é especialmente relevante na produção criminológica norte-americana. Num movimento que Jonh Hagan denominou como de inflexão na Era Reagan dos estudos criminológicos, observa-se a integração e a subordinação de pressupostos da criminologia desenvolvimentista (ou individualista) no contexto mais amplo da sociologia urbana (Hagan, 2012). Nesse sentido, os capítulos 6 e 10 merecem destaque. O primeiro representa uma contundente crítica à Teoria das Janelas Quebradas (Wilson \& Kelling, 1982). O objetivo do capítulo é discutir o efeito da reputação das vizinhanças sobre a durabilidade das desigualdades concentradas, ou seja, desloca a análise de aspectos socioeconômicos e étnico-raciais (comumente discutidos) para identidades e moralidades, as quais também apresentam efeito ativador das desigualdades. De outra forma, Sampson defende que as percepções de desordem são fundamentais para a compreensão do contexto social e constituem um efeito vizinhança por si, pois reforçam estigmas, moldam reputações e influenciam a trajetória da própria vizinhança (p. 123).

A tese central da Teoria das Janelas Quebradas é que incivilidades públicas (ou desordens) propiciam a ocorrência de crimes por indicarem que a comunidade não se importa com a vizinhança. Sampson critica essa proposição de duas maneiras principais:

a. a distinção entre desordem e crime é essencialmente precária e deve, primeiramente, considerar que

b. percepções de desordem são antes de tudo coletivas, compartilhadas coletivamente e reproduzidas socialmente (p. 123-134).

Com isso, o autor defende que tanto o crime como as desordens são variáveis dependentes numa equação que reúne como preditores estabilidade residencial, desvantagens concentradas, eficácia coletiva, dentre outros. Em suma, para o autor, não há relação causal entre desordem e crime.

Já no capítulo 10, Sampson explora a interdependência espacial entre as vizinhanças, por meio de características como pobreza, composição racial e imigração, e as possíveis relações com fenômenos sociais como crime e gravidez na adolescência. O autor argumenta em favor do agenciamento das vizinhanças e as suas influências recíprocas, constituindo uma rede ampla de relações sociais. Os resultados são tão relevantes quanto surpreendentes. Sampson demonstra como os comportamentos são influenciados pela lógica espacial e ainda como os padrões comunitários de desigualdade racial contribuem para a concentração de desvantagens. Por exemplo, são criadas barreiras culturais e estruturais para a mobilidade social. Além disso, Sampson desafia a suposição de coesão social e compartilhamento de valores co- 
muns ao demonstrar que a concentração de imigrantes funciona como "escudo" contra a violência. Nesse contexto, o aumento do número de famílias imigrantes está associado a menos crime, particularmente em bairros com maioria de imigrantes, o que ficou conhecido como o paradoxo latino (p. 252).

A repercussão de GAC tem sido intensa na criminologia dos Estados Unidos e de outros países ${ }^{5}$. Uma dimensão que deve ser destacada de forma especial é o potencial para a área de políticas públicas. Uma das conclusões possivelmente mais contundentes de GAC é o convite por intervenções em nível estrutural, não focadas exclusivamente nos indivíduos (cap. 5). Mais do que isso, a atuação de organizações capazes de interferir em contexto mais amplo, como agências estatais e grandes corporações, tem a possibilidade de conduzir um movimento coletivo de transformação social.

Em sua análise sobre o programa habitacional Moving to Opportunity (cap. 11), Sampson identifica não apenas limitações metodológicas, mas também as fronteiras de políticas dirigidas aos indivíduos. De forma geral, a crítica que estabelece é focada na participação e na responsabilidade do coletivo por meio de intervenções estruturais. Além disso, a análise de GAC proporciona insights para modelos de atuação interagências em políticas públicas, particularmente quando reconhece as diferentes dimensões de isolamento social que marcam determinados grupos sociais no contexto urbano (Wilson, 1987).

Por fim, na área de segurança pública, Sampson é preciso ao criticar políticas públicas que lidam com a desordem por meio de medidas de law and order, destacando tanto a falta de foco, por não se dirigirem às causas dos problemas, como a limitação quanto aos resultados, por suporem que percepções sobre desordens são uniformemente compartilhadas entre as pessoas (p. 131).

Sob o ponto de vista da generalização de GAC, o debate é intenso mesmo nos Estados Unidos. A apresentação de Chicago como "the quintessential American city" ( $p$. 76) foi motivo de discussão (Goering, 2013). Entretanto, Sampson justifica a sua escolha ao responder por motivações teóricas e pragmáticas, tendo peso relevante a representação étnico-racial dos principais grupos combinada com a variação de status socioeconômico.

Com efeito, a metodologia do Project on Human Development in Chicago Neighborhoods (PHDCN) está sendo replicada em outras cidades americanas, como Los Angeles, e estudos específicos do projeto foram utilizados em várias outras cidades e países, como Suécia, Austrália, Colômbia e China. O capítulo 7 traz os resul-
5. Especificamente em relação ao PHDCN, uma consulta livre no ICPSR sobre publicações relacionadas ao estudo original retorna mais de 500 registros e 170 estudos independentes. 
tados de um estudo comparativo entre Chicago e Estocolmo realizado pelo próprio autor em relação à eficácia coletiva e à violência. A conclusão de Sampson é de que a capacidade para o controle social é uma propriedade social, a qual pode ser observada e medida de forma adequada, mesmo com a influência de diferentes culturas e organizações sociais (p. 168).

Especificamente, a generalização do modelo para o Brasil e a América Latina em geral ensejou comentários do próprio autor. O contexto cultural e o padrão de urbanização dos países da região são condicionantes essenciais na utilização de conceitos como a eficácia coletiva (p. 167), particularmente por estar centrado em expectativas compartilhadas e confiança. Além disso, as interações entre público e privado impõem uma dificuldade adicional, em virtude da forma como as sociabilidades são informadas por instâncias de poder e sob o ponto de vista da prestação de serviços públicos. Como já foi destacado no caso da Colômbia (Cerda \& Morenoff, 2009), a presença de grupos criminosos organizados altera a forma como o controle social se realiza nas cidades. Ainda mais, a discussão etno-racial é central em GAC, particularmente acentuada pelo padrão de segregação espacial e suas consequências para a reprodução de diferenças sociais em nível vicinal.

De toda forma, o rigor metodológico, a precisão em aliar teoria e prática e a capacidade analítica do autor estão em inspiradora forma em GAC. Mesmo quem já conhecia a produção anterior do sociólogo encontrará na obra novidades significativas, com argumentos formulados e aperfeiçoados no livro, como é o caso especialmente da parte IV. No caso do Brasil, mesmo diante do aparente paradoxo nas relações positivas entre coesão social (Villarreal \& Silva, 2006), confiança, laços e densidade social e, ainda assim, altas taxas de criminalidade, como nas favelas brasileiras (Zaluar \& Ribeiro, 2009), encontra-se em GAC renovado estímulo em avançar teórica e metodologicamente na compreensão dos processos sociais que desvelam a concentração de crimes no espaço urbano brasileiro. Sem dúvida, é uma obra paradigmática na produção sociológica norte-americana, possivelmente sem precedentes na última década.

\section{Referências}

CERDA, Magdalena; MORENOFF, Jeffrey D. The limits of collective efficacy. Ann Harbor: University of Michigan, Department of Sociology, 2009.

GOERING, John. Neighborhood effects and public policy. City \& Community, v. 12, n. 1, p. 13-20, Mar. 2013. 
HAGAN, John. Who are the criminals?: The politics of crime policy from the age of Roosevelt to the age of Reagan. New Jersey: Princeton University Press, 2012.

PARK, Robert E; BURGESS, Ernest W; MCKENZIE, Roderick Duncan. The city. Chicago: University of Chicago Press, 1984 [1925].

SAMPSON, Robert J.; RAUDENBUSH, Stephen W.; EARLS, Felton. Neighborhoods and violent crime: a multilevel study of collective efficacy. Science, v. 277, n. 5.328, p. 918-924, Ago. 1997.

SAMPSON, Robert J; MORENOFF, Jeffrey D; EARLS, Felton. Beyond social capital: spatial dynamics of collective efficacy for children. American Sociological Review, $\mathrm{n}$. 64, p. 633-660, 1999.

SAMPSON, Robert J; MORENOFF, Jeffrey D; GANNON-ROWLEY, Thomas. Assessing neighborhood effects: social processes and new directions in research. Annual Review of Sociology, v. 28, p. 443-478, 2002.

SHAW, Clifford R.; MCKAY, Henry D. Juvenile delinquency and urban areas. Chicago: University of Chicago Press, 1969 [1942].

VILLARREAL, Andrés; SILVA, Braulio F. A. Social cohesion, criminal victimization and perceived risk of crime in Brazilian neighborhoods. Social Forces, v. 84, n. 3, p. 17251753, 2006.

WILSON, James Q; KELLING, George L. Broken windows. Atlantic Monthly, v. 249, n. 3, p. 29-38, 1982.

WILSON, William J. The truly disadvantaged: the inner city, the underclass, and public policy. Chicago: University of Chicago Press, 1987.

WIRTH, Louis. The ghetto. New Brunswick (NJ): Transaction Publishers, 1997 [1928]. ZALUAR, Alba; RIBEIRO, Ana Paula Alves. Teoria da eficácia coletiva e violência: o paradoxo do subúrbio carioca. Novos Estudos-Cebrap, n. 84, p. 175-196, 2009. 
